\title{
Determination of substrate composition, light, and temperature for interior plant growth
}

\author{
Shahzod Egamberdiev ${ }^{1 *}$, Mansurbek Kholmurotov $^{1}$, Erkin Berdiev ${ }^{1}$, Temurmalik Ochilov ${ }^{1}$, \\ Rustam Oymatov ${ }^{2}$, and Zoir Abdurakhmonov ${ }^{2}$ \\ ${ }^{1}$ Tashkent State Agrarian University, University str., 2, 100140, Tashkent province, Uzbekistan \\ ${ }^{2}$ Tashkent Institute of Irrigation and Agricultural Mechanization Engineers, 100000, Tashkent, \\ Uzbekistan
}

\begin{abstract}
This article presents the experimental results for determining the composition of the substrate, light and temperature for growing houseplants. Substrates were prepared in 8 different variants. The properties of the substrates were evaluated on the basis of 3 types: high, medium, and low. The amount of light required for the growth of houseplants is the result of a seasonal study. The effects of daily light fall and outdoor ambient temperature in the interior environment was studied for one year, and the results obtained were tabulated. According to the attitude of plants to light, they were divided into light-loving, semi-shade, shade-loving species.
\end{abstract}

\section{Introduction}

Soil, moisture, light, and temperature are very important factors for the growth and development of all plants. These factors also directly affect the interior plants. Although the external environment and the room environment are different, the climate in the external environment affects the room temperature and light $[1,2]$. Therefore, it is important to study it and provide suitable conditions for houseplants. For good growth and development of the plant, attention should be paid to the composition of the substrate for soil environment houseplants. The substrate consists of soil and other rocks prepared in different proportions [3].

A number of studies have been conducted worldwide on the growth and development of the ficus benjamina plant, and its various physiological conditions have been evaluated. Abdou, M.A., Mohamed, M.A.H. and Attia, F. A. have conducted a number of studies on the "Physiology of Ficus Benjamin Plants" and have argued that the preparation of cuttings depends on the physiological state of the plant. It was observed that the root rate of cuttings prepared in February decreased by $34 \%$, the root rate of cuttings harvested in June decreased by $87 \%$ and in October by $27 \%$ [3-7].

Abouzari, A., Rouhi, S., Eslami, A., \& Kaviani, B. conducted experiments on the evaluation of growth rates of ficus benjamina L. plant in different soilless environments. The effect of peat, perlite, composted tree bark, composted tea waste and rice husk selected

* Corresponding author: sh.egamberdiyev@tdau.uz 
as nutrient medium on plant height, stem diameter, number of side buds, root development was assessed [2].

The compounds in the plant composition that provide the growth rates that affect plant growth are calculated by Mbosso and others [6, 7]. Siddiqui and Hussain conducted their experiments in 2002 on the effectiveness of Indole Butyric Acid (IBA) in propagating ficus species and increasing rooting rates. 1000, 2000, 3000, 4000, $5000 \mathrm{ppm}$ and $0 \mathrm{ppm}$ amount options were used as the control option. The $4000 \mathrm{ppm}$ option was distinguished by its high performance [8].

Kayumov and Egamberdiyev studied the effects of organic fertilizers on the growth of ornamental plants as a result of experiments and provided data on growth rates [9, 10]. Houseplants with woody stems have been observed to grow more slowly than other categories of species. Veneklass and others studied the factors influencing the growth of ficus species and the physiology of the plant. This was compared with some similar species [11-14].

\section{Materials and methods}

In the study of substrate effects in intergroup plants, a 1:1:1:1 ratio (peat, soil, humus, and moisture-retaining additives) was adopted as the norm, taking into account that all houseplants are light, porous, have high nutritional value and grow well on permeable substrates [1-4]. In the experiments, different ratios of substrates were tested in 3 different variants. Soil, river sand, and humus feed in a 2:1:1 ratio were selected as a control option.

In studying the natural conditions and climate of the study area, the data of local meteorological stations, data obtained as a result of measuring the microclimate indicators of the room on special instruments were used.

\section{Results and discussion}

In the cultivation of houseplants are prepared taking into account such parameters as the composition of the substrate, its permeability, nutrient content, porosity. Substrates were tested in 8 different variants in different proportions to prepare a suitable substrate for houseplants. Natural and artificial nutrient units were used to prepare the substrate (Tables 1 and 2).

Table 1. List of natural and artificial feed units.

\begin{tabular}{|c|c|c|c|}
\hline \multicolumn{2}{|c|}{ Natural nutrient units } & \multicolumn{2}{c|}{ Artificial feed units } \\
\hline Name & Encryption icon & Name & Encryption icon \\
\hline Soil & $\mathrm{T}_{1}$ & Hydrogel & $\mathrm{C}_{1}$ \\
\hline Sand & $\mathrm{T}_{2}$ & Vermiculet & $\mathrm{C}_{2}$ \\
\hline Peat & $\mathrm{T}_{3}$ & Ionite & $\mathrm{C}_{3}$ \\
\hline Humus & $\mathrm{T}_{4}$ & Perlite & $\mathrm{C}_{4}$ \\
\hline Leaf rot & $\mathrm{T}_{5}$ & Zeolet & $\mathrm{C}_{5}$ \\
\hline Bark of coniferous trees & $\mathrm{T}_{6}$ & & \\
\hline Grain of cereals & $\mathrm{T}_{7}$ & & \\
\hline Coconut shell & $\mathrm{T}_{8}$ & & \\
\hline
\end{tabular}

In indoor plant growth rates, lighting is required to be a maximum of 10,000 lux and a minimum of 500 lux. Considering that the direct sunlight in summer is 50,000-100,000 in the outdoor environment and 5,000 lux on cloudy days, it was found that $6-10 \%$ of the light 
falls into the room depending on the location of the windows. In the ring corners of the room, this figure drops to $3-5 \%$. Natural light serves the course of biological processes in the plant. Under the influence of light, the growth processes in the plant decreased by 2-4 times. In conditions where there is a shortage of light, artificial lighting is carried out, using fluorescent lamps (optimal power $400 \mathrm{~W}$ per $1 \mathrm{~m}^{2}$ ), ultraviolet lamps and high-pressure sodium lamps. Artificial light sources provide 1,000-5,000 lux light, but light close to natural sunlight can only be grown using phytolamps in room corners and dark rooms where natural light does not reach, given the phytolamps only (Table 3 ).

Table 2. Properties of substrates prepared in different proportions.

\begin{tabular}{|c|c|c|c|c|c|c|c|c|}
\hline $\begin{array}{c}\text { Option } \\
\text { sequence } \\
\text { number }\end{array}$ & $\begin{array}{c}\text { B1 } \\
\text { control }\end{array}$ & B2 & B3 & B4 & B5 & B6 & B7 & B8 \\
\hline \multicolumn{9}{|l|}{ Properties } \\
\hline Ratio & $2: 1: 1$ & $1: 1: 1: 1$ & $2: 2$ & $1: 1: 1: 1$ & $2: 1: 1$ & $1: 1: 1: 1$ & $1: 1: 1: 1$ & $1: 1: 1: 1$ \\
\hline By names & 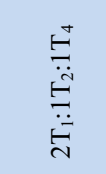 & 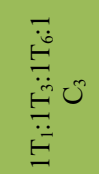 & $\stackrel{\stackrel{\sim}{*}}{\stackrel{\sim}{\sim}}$ & 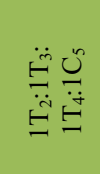 & 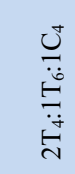 & 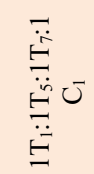 & 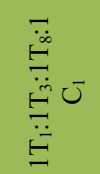 & 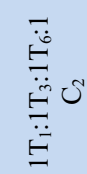 \\
\hline Nutrition & Avg. & High & Low & High & Avg. & Low & High & Avg. \\
\hline $\begin{array}{l}\text { Physical } \\
\text { properties and } \\
\text { porosity }\end{array}$ & Avg. & High & Low & High & Avg. & Low & High & Avg. \\
\hline $\begin{array}{c}\text { Chemical } \\
\text { properties and } \\
\text { pH }\end{array}$ & Avg. & High & Avg. & High & Avg. & Avg. & High & Avg. \\
\hline $\begin{array}{l}\text { Plant growth } \\
\text { rates }\end{array}$ & Avg. & High & Low & High & Avg. & Low & High & Avg. \\
\hline $\begin{array}{l}\text { Moisture } \\
\text { retention }\end{array}$ & Low & Avg. & Low & High & Avg. & Avg. & High & Avg. \\
\hline $\begin{array}{c}\text { Ease of } \\
\text { disease } \\
\text { development }\end{array}$ & Avg. & Avg. & Avg. & Avg. & Avg. & High & Avg. & Avg. \\
\hline
\end{tabular}

However, this incurs a number of costs. In the experiments, we used sunlight (average 4,000 lux) from the north-east windows of the room and artificial lighting that could provide 2,000 lux. In the assessment, we reviewed plant growth, leaf condition and color, bud development, new leaf formation, and transition to the dormant period. The experiment was conducted sequentially in the seasons (see Table 4). 
Table 3. Natural and artificial light sources impact on ficus plants.

\begin{tabular}{|c|c|c|c|c|c|c|c|c|}
\hline \multirow[b]{2}{*}{ 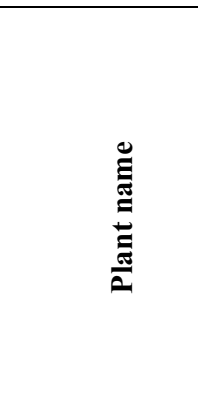 } & \multicolumn{2}{|c|}{ Spring } & \multicolumn{2}{|c|}{ Summer } & \multicolumn{2}{|c|}{ Autumn } & \multicolumn{2}{|c|}{ Winter } \\
\hline & 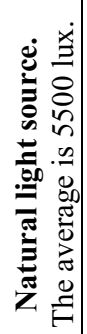 & 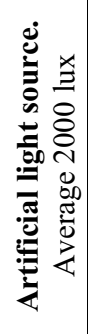 & 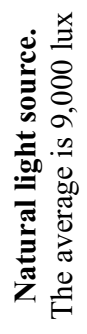 & 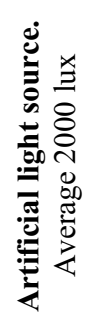 & 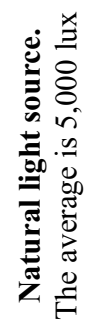 & 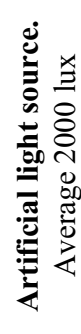 & 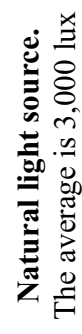 & 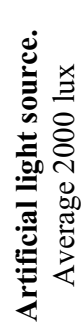 \\
\hline Great kalate & 2.4 & 1.4 & 2.3 & 1.3 & 1.4 & 1.3 & 0.4 & 0.2 \\
\hline Chlorophytum & 2.7 & 1.5 & 2.6 & 1.4 & 1.7 & 1.2 & 0.5 & 0.4 \\
\hline Benjamin ficus & 2.3 & 1.3 & 2.3 & 1.2 & 1.4 & 1.2 & 0.3 & 0.2 \\
\hline Elastic ficus & 2.4 & 1.5 & 2.2 & 1.1 & 1.2 & 1.1 & 0.2 & 0.1 \\
\hline Fern & 2.2 & 1.3 & 2.1 & 1.3 & 1.4 & 1.3 & 0.4 & 0.2 \\
\hline Differenbaxiya & 2.3 & 1.2 & 2.3 & 1.2 & 1.1 & 1.2 & 0.2 & 0.1 \\
\hline $\begin{array}{l}\text { Dratsena } \\
\text { marginata }\end{array}$ & 2.4 & 1.8 & 2.4 & 1.9 & 1.8 & 1.4 & 0.5 & 0.4 \\
\hline Spatafillium & 2.6 & 1.7 & 2.5 & 1.6 & 1.5 & 1.1 & 0.4 & 0.2 \\
\hline
\end{tabular}

Note: 1.1-1.0 growth rate is sluggish; 1.0-2.0 extinction rates are average; and, 2.0-3.0 growth rates are accelerating.

Table 4. Daily fall of natural light and the effect of external ambient temperature on room temperature (Laboratory room of the Department of Ornamental Horticulture).

\begin{tabular}{|c|c|c|c|c|c|c|}
\hline \multirow[t]{2}{*}{ Months } & \multirow[t]{2}{*}{$\begin{array}{l}10 \text { days in } \\
\text { a month } \\
\text { (decades) }\end{array}$} & \multirow{2}{*}{$\begin{array}{c}\text { Daily } \\
\text { average } \\
\text { natural } \\
\text { light } \\
\text { fall, hrs }\end{array}$} & \multirow{2}{*}{$\begin{array}{c}\text { Effect of } \\
\text { natural light } \\
\text { on room } \\
\text { temperature, } \\
\text { average }^{\circ} \mathrm{C}\end{array}$} & \multirow[t]{2}{*}{$\begin{array}{c}\text { Average } \\
\text { temperature } \\
\text { of the room, } \\
{ }^{\circ} \mathrm{C}\end{array}$} & \multicolumn{2}{|c|}{$\begin{array}{c}\text { Average } \\
\text { temperature of the } \\
\text { external } \\
\text { environment, }{ }^{\circ} \mathrm{C} \\
\end{array}$} \\
\hline & & & & & Dawn & Night \\
\hline \multirow{4}{*}{ January } & Decade & 6 & +4 & +17 & +3 & -5 \\
\hline & Decade & 7 & +5 & +17 & +4 & -3 \\
\hline & Decade & 6 & +4 & +15 & +2 & -7 \\
\hline & Decade & 5 & +3 & +16 & +3 & -4 \\
\hline \multirow{4}{*}{ February } & Decade & 7 & +5 & +17 & +3 & -3 \\
\hline & Decade & 6 & +4 & +17 & +4 & -3 \\
\hline & Decade & 6 & +4 & +17 & +4 & -3 \\
\hline & Decade & 7 & +5 & +18 & +5 & -2 \\
\hline \multirow{4}{*}{ March } & Decade & 8 & +6 & +18 & +8 & +2 \\
\hline & Decade & 9 & +7 & +18 & +9 & +4 \\
\hline & Decade & 10 & +8 & +19 & +9 & +5 \\
\hline & Decade & 10 & +8 & +20 & +10 & +5 \\
\hline \multirow{4}{*}{ April } & Decade & 11 & +9 & +20 & +15 & +4 \\
\hline & Decade & 10 & +8 & +21 & +17 & +5 \\
\hline & Decade & 11 & +9 & +20 & +18 & +7 \\
\hline & Decade & 10 & +8 & +21 & +18 & +8 \\
\hline \multirow{4}{*}{ May } & Decade & 11 & +9 & +22 & +20 & +10 \\
\hline & Decade & 11 & +9 & +21 & +21 & +9 \\
\hline & Decade & 12 & +10 & +20 & +20 & +12 \\
\hline & Decade & 11 & +9 & +21 & +25 & +13 \\
\hline \multirow{2}{*}{ June } & Decade & 13 & +11 & +22 & +30 & +11 \\
\hline & Decade & 15 & +13 & +24 & +35 & +15 \\
\hline
\end{tabular}




\begin{tabular}{|c|c|c|c|c|c|c|}
\hline & Decade & 15 & +13 & +26 & +34 & +17 \\
\hline & Decade & 14 & +12 & +26 & +38 & +19 \\
\hline \multirow{4}{*}{ July } & Decade & 15 & +13 & +28 & +36 & +20 \\
\hline & Decade & 14 & +12 & +27 & +35 & +22 \\
\hline & Decade & 14 & +12 & +27 & +32 & +20 \\
\hline & Decade & 15 & +13 & +26 & +30 & +18 \\
\hline \multirow{4}{*}{ August } & Decade & 15 & +13 & +26 & +30 & +17 \\
\hline & Decade & 14 & +12 & +25 & +28 & +16 \\
\hline & Decade & 15 & +13 & +24 & +25 & +15 \\
\hline & Decade & 16 & +14 & +24 & +27 & +13 \\
\hline \multirow{4}{*}{ September } & Decade & 15 & +13 & +22 & +24 & +14 \\
\hline & Decade & 15 & +13 & +23 & +28 & +12 \\
\hline & Decade & 14 & +12 & +22 & +24 & +11 \\
\hline & Decade & 13 & +11 & +19 & +21 & +10 \\
\hline \multirow{4}{*}{ October } & Decade & 13 & +11 & +17 & +20 & +7 \\
\hline & Decade & 12 & +10 & +17 & +17 & +8 \\
\hline & Decade & 11 & +9 & +16 & +15 & +5 \\
\hline & Decade & 12 & +10 & +17 & +13 & +6 \\
\hline \multirow{4}{*}{ November } & Decade & 12 & +10 & +18 & +11 & +4 \\
\hline & Decade & 10 & +8 & +18 & +10 & +3 \\
\hline & Decade & 9 & +7 & +19 & +7 & +2 \\
\hline & Decade & 10 & +8 & +20 & +6 & +1 \\
\hline \multirow{4}{*}{ December } & Decade & 8 & +6 & +19 & +5 & -2 \\
\hline & Decade & 7 & +5 & +18 & +3 & -3 \\
\hline & Decade & 7 & +5 & +17 & +4 & -3 \\
\hline & Decade & 6 & +4 & +15 & +2 & -7 \\
\hline
\end{tabular}

\section{Conclusions}

Substrate in a 1:1:1:1 ratio of soil, peat, coconut shell, and hydrogel is recommended for growing houseplants. It was found that natural light is required to be 5,000 lux for plant growth in the interior. It is recommended to use artificial lighting for plants grown in corners of the room in low sunlight. The illuminance of artificial lighting is required to be not less than 2000 lux.

A favorable temperature for the growth of houseplants is required to be in the range of + 18-24 ${ }^{\circ} \mathrm{C}$. In winter it is necessary to protect from the effects of heating means. In Uzbekistan, an increase in summer temperature to $+35-40{ }^{\circ} \mathrm{C}$ causes an increase in room temperature to $+12{ }^{\circ} \mathrm{C}$ and damages plants. At this time it is necessary to keep the room cool and water 5-6 times a day.

\section{References}

1. M.A. Abdou, M.A.H. Mohamed, F.A. Attia, Journal of Agricultural Science, 29(2), 775-785 (2004)

2. A. Abouzari, S. Rouhi, A. Eslami, B. Kaviani, International Journal of Agriculture and Biology, 14(6), 11 (2012)

3. H. Babaie, H. Zarei, K. Hemmati, Journal of Ornamental Plants, 4(2), 75-79 (2014)

4. A. Djuraev, D. Mirdjalalov, A. Nuratdinov, T. Khushvaktov, Y. Karimov, E3S Web of Conferences, 258, 03017 (2021) 
5. S. Ercisli, O. Anapali, A. Esitken, U. Sahin, Gartenbauwissenschaft, 67(1), 34-38 (2002)

6. E. Berdiyev, Sh. Egamberdiyev, Agroprocessing, 4(2), 9 (2020)

7. E. Berdiyev, Sh. Amanbayeva, Sh. Egamberdiyev, Agroprocessing, 4(1), 10 (2019)

8. Y. Gafforov, R. Phookamsak, H.-B. Jiang, D.N. Wanasinghe, M. Juliev, Botany, 97(12), 671-680 (2019)

9. B. Abdullaev, R.A. Kulmatov, A.A. Kist, Industrial Laboratory (USSR) (English translation of Zavodskaya Laboratoriya), 54(7), 710-713 (1989)

10. T. Kayumov, S. Egamberdiyev, Agroprocessing, 4(1), 11 (2019)

11. A.M. Khomami, M.M. Zadeh, International Journal of Agriculture and Crop Sciences (IJACS), 6(7), 361-363 (2013)

12. V.S. Savenko, R.A. Kulmatov, Geochemistry International, 35(11), 1028-1030 (1997)

13. M.I. Siddiqui, S.A. Hussain, Sarhad Journal of Agriculture, 23(4), 919-925 (2007)

14. R.A. Kulmatov, V.S. Savenko, N. Dalonov, Geochemistry International, 29(5), 140148 (1992) 